\title{
Laboratory Culture of the Pelagic Blue-Green Alga Trichodesmium thiebautii: Conditions for Unialgal Culture
}

\author{
Kaori Ohki and Yoshihiko Fujita* \\ Ocean Research Institute, University of Tokyo, Nakano, Tokyo 164, Japan
}

\begin{abstract}
We investigated conditions for laboratory culture of the pelagic blue-green alga Trichodesmium thiebautii and conducted supplementary experiments with Trichodesmium erythraeum. T. thiebautii grew in the $\mathrm{f}$ ' medium of Guillard and Ryther after careful removal of living contaminants, especially larvae of the copepod Macrosetella gracilis, from bundle colonies under the microscope. Spherical colonies were not suitable for the inoculum. $T$ thiebautii appears to be auxotrophic, at least in terms of $B_{12}$ requirement, under our culture conditions. $T$ erythraeum survived up to $100 \mathrm{~d}$ in ' $\mathrm{f}$ ' medium but failed to grow actively.
\end{abstract}

\section{INTRODUCTION}

Trichodesmium thiebautii and $T$. erythraeum are pelagic blue-green algae, distributed widely in tropical and subtropical seas. Although attention has been paid to the genus Trichodesmium as an important nitrogen fertilizer (Dugdale et al., 1961; Dugdale and Goering, 1964; Goering et al., 1966; Taylor et al., 1973; Carpenter and McCarthy, 1975; Saino and Hattori, $1978,1979)$, many of their unique characteristics have remained unknown. Two examples: (1) Although Trichodesmium is a member of the Oscillatoriaceae and hence does not form heterocysts, it is able to fix atmospheric nitrogen under aerobic conditions as effectively as heterocystous algae (Goering et al., 1966; Taylor et al., 1973). (2) Trichodesmium is found mainly in open sea areas very poor in nutrients and even here sometimes forms dense blooms (Goering et al., 1966; Marumo and Asaoka, 1974a; Carpenter and McCarthy, 1975); such oligotrophy is unusual in marine bluegreen algae, most of which live in littoral and coastal areas rich in nutrients. In order to investigate these physiological and biochemical peculiarities, stable laboratory cultures are of great importance. However, thus far attempts at laboratory culture of Trichodesmium have been rather unsuccessful. Ramamurthy was

- Addressee for mail the first to report successful axenic culture of $T$. erythraeum in modified Erdschreiber medium (Ramamurthy, 1972). However, this medium contained antibiotics (which might cause genetic mutation of wild strains), and it was not possible to repeat his experiment. Carpenter and McCarthy (1975) succeeded in maintaining $T$. thiebautii alive in 'f' medium of Guillard and Ryther for over $100 \mathrm{~d}$. However, they failed to obtain active growth.

As a first step towards a stable, axenic culture of Trichodesmium, the conditions for unialgal culture were surveyed with $T$. thiebautii and supplementarily with $T$. erythraeum collected from Kuroshio waters, Japan. Finally we succeeded in establishing conditions for continued unialgal culture of $T$. thiebautii, and in keeping $T$. erythraeum alive for up to $100 \mathrm{~d}$, albeit without active growth.

\section{MATERIALS AND METHODS}

Trichodesmium thiebautii and $T$. erythraeum were collected from surface waters about $10 \mathrm{~km}$ south of Iroh-Saki, Izu-Peninsula on July 28 and 29, September 14 and October 6, 1980. In July, T. thiebautii was dominant, in September and October both $T$. thiebautii and $T$. erythraeum were present in large numbers. 
Samplings were made by hand-net surface tow $(20 \mathrm{~cm}$ net diameter, $40 \mu \mathrm{m}$ nylon mesh) of 1 to 2 min duration. The samples were diluted with sea water immediately after each tow. Trichodesmium colonies were separated with a Pasteur pipet and re-suspended in the surface water filtrated through Millipore HA filter. Separation was achieved within $2 \mathrm{~h}$ after sampling.

Most Trichodesmium thiebautii forms colonies, either spherical or bundle. Spherical colonies consisted of aged trichomes and contained numerous microorganisms, such as bacteria, fungi, ciliates and diatoms; hence they were not suitable for starting cultures. Since bundle colonies contained fewer microorganisms and seemed to consist of more active trichomes, we used these as inocula. However, the colonies often contained nauplius or early copepodid stages of Macrosetella gracilis which is known to feed on Trichodesmium (cf. Björnberg, 1965; Roman, 1978). Therefore, we first carefully removed $M$. gracilis from bundle colonies under a low-power binocular, and washed the colonies several times with Millipore-filtered sea water before inoculation. The "f" medium of Guillard and Ryther (1962), without addition of $\mathrm{Na}_{2} \mathrm{SiO}_{3}$, was used as basic culture medium: it was diluted 2 to 40 times with Millipore-filtered surface water of the Kuroshio area $(34.1 \%$ S). Screw-capped test tubes made of hard glass were used as culture vessels. They were first soaked in dilute $\mathrm{HCl}$, then rinsed well with de-ionized water to eliminate contaminating heavy metals.

For survival tests, 1 to 3 bundle colonies, consisting of 10 to 20 trichomes, were inoculated into $10 \mathrm{ml}$ of sterilized medium. Seven to 20 batches were set up for each condition to be tested, and the number of batches in which cells survived was counted and listed in Tables as a function of incubation period. The cells were incubated at $23^{\circ} \mathrm{C} \pm 2 \mathrm{C}^{\circ}$ in fluorescent light (day-light type) and/or day light; light intensity ranged from 300 to 3000 lux. Fluorescent light appeared to be inhibitory; hence most experiments were done in day light. The light/dark regime September, 1980 to Janu- ary, 1981) was 13.9:10.1 (light: dark) to 10.9:13.1. All colonies were transferred into fresh medium every 3 to $5 \mathrm{~d}$ in the initial phase of incubation, later every 20 to $30 \mathrm{~d}$. For the growth test, several trichomes ( 3 to 8 ) of 150 to 250 cells were inoculated into each batch $(10 \mathrm{ml})$, and the number of trichomes was counted up to the formation of bundle colonies.

\section{RESULTS}

\section{Conditions for Long-Term Survival}

Trichodesmium cells - both $T$. thiebautii and T. erythraeum - tend to die and disintegrate quickly, when incubated under artificial conditions. Hence we first analyzed the prerequisites for survival.

Table 1 shows the effect of nitrogen on survival for Trichodesmium thiebautii collected in September. $\mathrm{NO}_{3}{ }^{-}$or $\mathrm{NH}_{3}$ was added to nitrogen-free " $\mathrm{f}$ " medium as indicated. Results indicate that (1) T. thiebautii can survive for over $100 \mathrm{~d}$ without combined nitrogen. (The same holds true for $T$. erythraeum); (2) ammonia is toxic, even at concentrations as low as $30 \mu \mathrm{M}$. Ammonia has been known as a nitrogen source assimilated. with a very low $\mathrm{Km}$ value by this alga (Saino, 1978), and the effect observed here appears to be due to its toxicity generally observable in algae cultured in an alkaline medium.

Vitamin $B_{12}$ is an essential growth factor for many phytoplankters; some of them can utilize not only cyanocobalamin but also its derivatives (Provasoli and Carlucii, 1974). As shown in Table 2, both Trichodesmium erythraeum and $T$. thiebautii survived for distinctly longer period in the medium containing hydroxo-cobalamin. Though $T$. erythraeum survived only for $76 \mathrm{~d}$ in this experiment, survival for more than $100 \mathrm{~d}$ was observed several times in other experiments. Trichodesmium is probably auxotrophic: it requires at least $\mathrm{B}_{12}$ the specificity for $\mathrm{B}_{12}$ derivatives may be of the Escherichia coli- or Lactobacillus leichmanii-type (cf. Provasoli and Carlucii, 1974).

Table 1 Trichodesmium thiebautii. Effect of nitrogen on survival. Illumination: combined fluorescent and daylight. The culture medium for each batch was renewed every 3 to $5 \mathrm{~d}$ during the early period of incubation; later, every 20 to $30 \mathrm{~d}$. $\mathrm{f} / 10 \mathrm{and} \mathrm{f} / 40$ : $1 / 10$ diluted and $1 / 40$ diluted ' $f$ ' medium, respectively

\begin{tabular}{|c|c|c|c|c|c|c|c|c|c|c|c|c|c|}
\hline \multirow[t]{2}{*}{ Medium } & \multirow{2}{*}{$\begin{array}{c}\text { Number of } \\
\text { batches tested }\end{array}$} & \multirow{2}{*}{$\begin{array}{c}\mathrm{NaNO}_{3} \\
(\mu \mathrm{M})\end{array}$} & \multirow{2}{*}{$\begin{array}{c}\mathrm{NH}_{4} \mathrm{Cl} \\
(\mu \mathrm{M})\end{array}$} & \multicolumn{10}{|c|}{ Incubation (d) } \\
\hline & & & & 5 & 8 & 12 & 16 & 19 & 25 & 36 & 54 & 83 & 100 \\
\hline & & & & \multicolumn{10}{|c|}{ ( $\%$ of survival) } \\
\hline \multirow{3}{*}{$\mathfrak{f} / 10$} & 20 & 177 & 0 & 95 & 95 & 80 & 65 & 55 & 45 & 45 & 20 & 10 & 0 \\
\hline & 33 & 0 & 0 & 97 & 64 & 58 & 45 & 42 & 36 & 24 & 18 & 3 & 3 \\
\hline & 7 & 0 & 30 & 86 & 57 & 43 & 14 & 0 & 0 & 0 & 0 & 0 & 0 \\
\hline \multirow{3}{*}{$\mathrm{f} / 40$} & 18 & 89 & 0 & 100 & 83 & 80 & 73 & 50 & 22 & 20 & 0 & 0 & 0 \\
\hline & 22 & 0 & 0 & 100 & 77 & 73 & 64 & 36 & 27 & 18 & 9 & 5 & 5 \\
\hline & 9 & 0 & 30 & 89 & 56 & 44 & 22 & 11 & 0 & 0 & 0 & 0 & 0 \\
\hline
\end{tabular}


Table 2. Trichodesmium thiebautii and $\mathrm{T}$ erythraeum. Effect of hydroxocobalamin on survival. $\mathrm{NO}_{3}$-free f/40 medium, daylight. Medium of each batch was renewed every 3 to $5 \mathrm{~d}$ during the early period of incubation; later, every 20 to $30 \mathrm{~d}$

\begin{tabular}{|c|c|c|c|c|c|c|c|c|c|c|c|c|c|c|}
\hline \multirow[t]{2}{*}{ Species } & \multirow{2}{*}{$\begin{array}{l}\text { Hydroxo- } \\
\text { cobalamin } \\
\left(\mu \mathrm{g} \mathrm{l}^{-1}\right)\end{array}$} & \multirow{2}{*}{$\begin{array}{c}\text { Number of } \\
\text { batches } \\
\text { tested }\end{array}$} & \multicolumn{12}{|c|}{ Incubation (d) } \\
\hline & & & 2 & 5 & 7 & 12 & 17 & 25 & 35 & 61 & 76 & 81 & 98 & 100 \\
\hline & & & \multicolumn{12}{|c|}{ ( $\%$ of survival) } \\
\hline \multirow{2}{*}{ T. thiebautii } & 1.5 & 10 & 100 & 100 & 100 & 100 & 100 & 90 & 60 & 50 & 50 & 50 & 40 & 10 \\
\hline & 0 & 14 & 100 & 86 & 86 & 86 & 86 & 57 & 36 & 14 & 14 & 7 & 7 & 0 \\
\hline \multirow[t]{2}{*}{$T$ erythraeum } & 1.5 & 12 & 100 & 100 & 92 & 92 & 83 & 75 & 50 & 8 & 8 & 0 & 0 & 0 \\
\hline & 0 & 9 & 100 & 89 & 89 & 78 & 33 & 0 & 0 & 0 & 0 & 0 & 0 & 0 \\
\hline
\end{tabular}

\section{Conditions for Active Growth of Trichodesmium thiebautii}

A sample collected in October survived in hydroxocobalamin-enriched and $\mathrm{NO}_{3}{ }^{-}$-free "f" medium of $1 / 40$ strength (Table 2) and began to grow after a rest of $96 \mathrm{~d}$. Once the alga started to grow, active growth was found to be reproducible even under conditions that earlier caused the long rest. The growth patterns obtained in " $f$ " medium of various nutritional strength, with and without $\mathrm{NO}_{3}{ }^{-}$or hydroxocobalamin, are presented semiquantitatively in Table 3 . When separate trichomes were inoculated, each trichome first increased in length up to $3 \mathrm{~mm}$. Then, it split mechanically into 2 to 3 daughter trichomes. The general pattern was as follows: (1) Increase in trichome number starting after a long lag period (about $10 \mathrm{~d}$ ), which was not shortened after adding vitamins; elongation of trichomes occurring at the end of this lag period. (2) The number of separate trichomes increased, without colony formation; bundle colonies appeared when the trichome population reached 15 to 20 per $10 \mathrm{ml}$. Though the size of trichomes in the cultures was variable, average size was almost constant throughout the culture period. Thus increase in trichome number (Table 3) suggests that the $\mu$ value under our culture conditions was as high as 0.1 to $0.3 \mathrm{~d}^{-1}$ and is not affected by added nitrogen or by added vitamin $\mathrm{B}_{12}$; no significant difference was observable in media of $1 / 5$ to $1 / 40$ strength.

Trichomes were examined microscopically parallel to growth tests. In all cases, trichomes grown in test tubes showed the same morphological characteristics as those in the natural habitat. Average cell width ranged from 8 to $11 \mu \mathrm{m}$, and the ratio of cell width to cell height was almost unity or a little less; the tapered form at the end of trichome was also maintained (Fig. 1A vs. B, C, D). These characteristics were not altered by nutritional conditions (Fig. 1B vs. C). This provides proof that we observed the growth of Trichodesmium thiebautii, and not of any other, contaminating blue-green alga.

Table 3. Trichodesmium thiebautii. Growth under various nutritional conditions. Daylight illumination. C: some trichomes formed bundle colonies

\begin{tabular}{|c|c|c|c|c|c|c|c|c|c|c|c|c|}
\hline \multirow{2}{*}{ Medium } & \multirow{2}{*}{$\begin{array}{c}\mathrm{NaNO}_{3} \\
(\mu \mathrm{M})\end{array}$} & \multirow{2}{*}{$\begin{array}{l}\text { Hydroxocobalamin } \\
\qquad\left(\mu g \mathrm{I}^{-1}\right)\end{array}$} & \multicolumn{10}{|c|}{ Incubation (d) } \\
\hline & & & 0 & 3 & 6 & 8 & 11 & 14 & 16 & 18 & 22 & 26 \\
\hline \multirow{3}{*}{$\mathrm{f} / 5$} & & & \multicolumn{10}{|c|}{ (Number of trichomes) } \\
\hline & 353 & 0 & 4 & 5 & 5 & 4 & 4 & 8 & 10 & 15 & 20 & $\mathrm{C}$ \\
\hline & 0 & 0 & 3 & 5 & 2 & 6 & 5 & 12 & 15 & C & C & $\mathrm{C}$ \\
\hline \multirow{4}{*}{$f / 10$} & 177 & 0 & 8 & 8 & 10 & 10 & 10 & 15 & 20 & 20 & $\mathrm{C}$ & $\mathrm{C}$ \\
\hline & 0 & 0 & 3 & 3 & 4 & 3 & 3 & 7 & 9 & 10 & 15 & $\mathrm{C}$ \\
\hline & 177 & 1.5 & 3 & 4 & 7 & 5 & 4 & 7 & 8 & 8 & 15 & 20 \\
\hline & 0 & 1.5 & 3 & 1 & 6 & 6 & 6 & 13 & 15 & 20 & C & C \\
\hline \multirow{4}{*}{$\mathrm{f} / 40$} & 45 & 0 & 3 & 2 & 5 & 3 & 3 & 5 & 5 & 6 & 10 & 10 \\
\hline & 0 & 0 & 6 & 5 & 10 & 7 & 5 & 15 & 20 & C & C & C \\
\hline & 45 & 1.5 & 3 & 1 & 4 & 4 & 2 & 6 & 4 & 6 & 8 & 20 \\
\hline & 0 & 1.5 & 7 & 5 & 5 & 4 & 5 & 10 & 15 & C & C & C \\
\hline
\end{tabular}




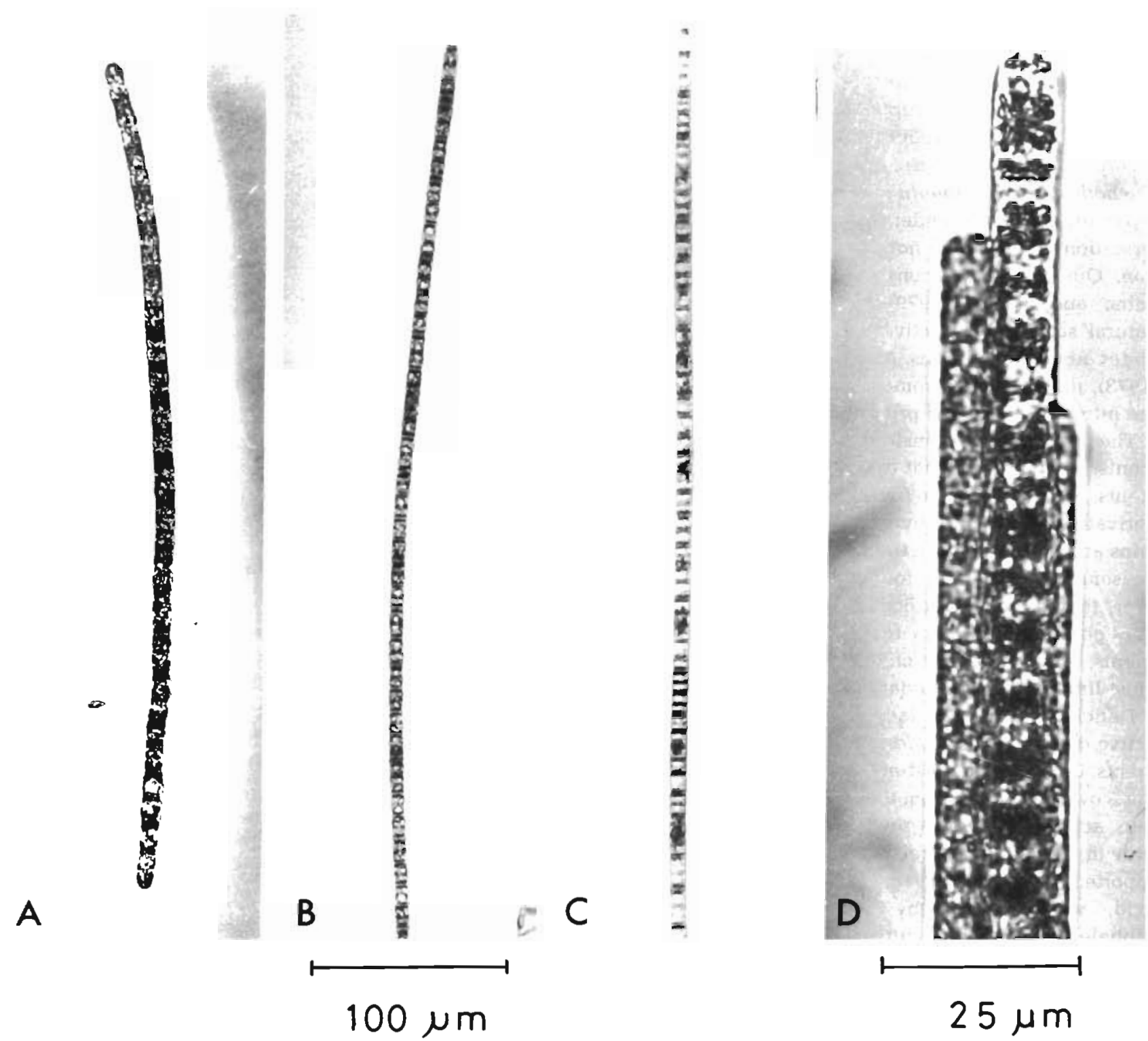

Fig. 1. Trichodesmium thiebautii. Microphotographs collected from natural habitats (A) and grown in laboratory culture $\left(\mathrm{B}_{1} \mathrm{C}\right.$ and D). A: trichome collected in October, $1980 ; \mathrm{B}$ : grown in $\mathrm{f} / 40$ medium free of $\mathrm{NO}_{3}$ but with hydroxocobalamin $\left(1.5 \mu \mathrm{g}^{-1}\right) ; \mathrm{C}$ : grown in $\mathrm{f} / 40$ medium containing $\mathrm{NO}_{3}(45 \mu \mathrm{M})$ and hydroxocobalamin $\left(1.5 \mu \mathrm{g} \mathrm{l}^{-1}\right)$; $\mathrm{D}$ : bundle colony formed in $\mathrm{C}$ conditions. Duration: $33 \mathrm{~d}$

\section{DISCUSSION}

Of primary importance for the successful cultivation of Trichodesmium is the careful elimination of living contaminants from algal colonies to be inoculated. In our cultures, appreciable growth of microbial contaminants did not occur, and medium renewal was not required as often as suggested by Ramamurthy (1972). When the colonies or trichomes were carefully washed with sterilised sea water under the microscope, both $T$. thiebautii and $T$. erythraeum survived at least for 80 to $90 \mathrm{~d}$ in the same medium. The rapid disintegration occurring under artificial conditions is probably mainly due to living contaminants, especially the grazing of Macrosetella gracilis. Of secondary importance seems to be the protection from excessive heavy metals. Although we can use ordinary glassware for the culture vessels, washing with dilute $\mathrm{HCl}$ seems to be essential for successful Trichodesmium cultivation. The cultures tended to be more stable in media with lower nutrient concentrations $(\sim 1 / 40)$. Heavy metal contaminants in reagents used as nutrients are probably toxic and render the cultures unstable.

The growth rates suggested by our data were appreciably higher than those reported for natural populations 10.02 to $0.008 \mathrm{~d}^{-1}$, Carpenter and McCar- 
thy, 1975; Saino, 1978; McCarthy and Carpenter, 1979). Insignificant differences in growth rates with and without $\mathrm{NO}_{3}{ }^{-}$indicate that nitrogen supply from nitrogen fixation can support algal growth as efficiently as the $\mathrm{NO}_{3}{ }^{-}$-reduction system. Since growth occurred in separated trichomes, nitrogen fixation of Trichodesmium thiebautii can be appreciable, even in separated trichomes under aerobic conditions; colonyformation is, therefore, not essential for nitrogen fixation. Our results are consistent with the finding by Saino and Hattori (1979) that single trichomes of natural samples are active in nitrogen fixation even under aerobic conditions. As suggested by Taylor et al. (1973), there must be some mechanism for protecting the nitrogenase system present in the cells.

The $B_{12}$ effect was insignificant in growth experiments, in contrast to that observed in survival experiments. We also failed to find a stimulative effect of $\mathrm{B}_{12}$ derivatives other than hydroxocobalamin. Other vitamins and micrometals in the " $\mathrm{f}$ " medium were found to be somewhat effective for long-term survival. However, they were insignificant in growth experiments. Though Trichodesmium thiebautii requires micronutrients, some other factors - chemical or physical must limit its growth under our conditions.

Deficiency in such factors may have prevented active growth of Trichodesmium in our earlier experiments. During a long resting period, $T$. thiebautii tends to recover gradually from the deficiency so as to facilitate active but slow growth; the factors still limit growth, even after recovery. Ramamurthy (1972) reported that the plant growth hormone, gibbelelic acid, was required by $T$. erythraeum. However, gibbelelic acids, aminopurine derivatives and kinetin were not stimulative but inhibitory. Search for the factors in question must be of primary importance for the establishment of axenic cultures; it is now in progress, using the unialgal cultures obtained.

The evidence that both Trichodesmium thiebautii and $T$. erythraeum can survive for a long period without active growth may explain the wide distribution of these algae in the tropical and subtropical sea areas. Because of their long survival (resting conditions), they can be transported by water currents to areas very distant from where they had grown actively; whenever the environmental conditions become advantageous, they will start to grow again. A dense Trichodesmium population often appears in the East China Sea and along the coast of Japan (Nagasawa and Marumo, 1967; Marumo and Asaoka, 1974 a, b). This may be the result of active growth of trichomes transported by the Kuroshio from tropical sea areas.

Acknowledgements. This study was supported by the JapanUS Cooperative Science Program (VPS-MBR 202). Coopera- tion of Professor C. Van Baalen, Marine Science Institute, University of Texas at Austin (R-XMB-0093) and support from a Grant-in-Aid for Cooperative Research (A-534027) from the Ministry of Education, Science and Culture, Japan is acknowledged. We wish to express our thanks to Professors $H$. Watanabe and Y Yokohama and Mr Ueda, and all the staff of Shimoda Marine Research Center, Tsukuba University, as well as to Professor M. Takahashi of the Dept. of Biological Science, Tsukuba University, and Dr $T$ Ishimaru of the Ocean Research Institute, University of Tokyo for help during this study.

\section{LITERATURE CITED}

Björnberg, T K. S. (1965). Observations on the development and the biology of the Maracdaea Dana (Copepodo: Crystacea). Bull. mar Sci, 15: 512-520

Carpenter, E. J., McCarthy, J. J. (1975). Nitrogen fixation and uptake of combined nitrogenous nutrients by Oscillatoria (Trichodesmium) thiebautii in the western Sargasso Sea. Limnol. Oceanogr. 20: 389-401

Dugdale, R. C., Menzel, D. W., Ryther H. (1961). Nitrogen fixation in the Sargasso Sea. Deep Sea Res. 7: 298-300

Dugdale, R. C., Goering, J. J. (1964). High nitrogen fixation in the Sargasso Sea and Arabic Sea. Limnol. Oceanogr. 9: $507-510$

Goering, J. J., Dugdale, R. C., Menzel, D. W. (1966). Estimates of in situ rate of nitrogen uptake by Trichodesmium sp. in the tropical Atlantic Ocean. Limnol. Oceanogr 11: $614-620$

Guillard, R. R., Ryther, J. H. (1962). Studies of marine planktonic diatomes. I. Cyclotella nana Hustedt, and Detonula confervaces (Cleve) Gran. Can. J. Microbiol. 8: 229-239

Marumo, R. Asaoka, O. (1974a). Distribution of pelagic bluegreen algae in the North Pacific Ocean. J. oceanogr. Soc. Japan 30: 77-85

Marumo, R., Asaoka, O. (1974b). Trichodesmium in the East China Sea. 1 Distribution of Trichodesmium thiebautis Gomont during 1961-1967 J. oceanogr Soc. Japan 30: 298-303

McCarthy, J. J., Carpenter, E. J. (1979). Oscillatoria (Trichodesmium) thiebautii (Cyanophyta) in the centra] north Atlantic Ocean. J. Physiol. 15: 75-82

Nagasawa, S., Marumo, R. (1967). Taxonomy and distribution of Trichodesmium (Cyanophyceae) in the Kuroshio water. Information Bull, Planktol. Japan. Commemoration number of Dr Y Matsue: 139-143

Provasoli, L., Carlucii, A. F. (1974). Vitamins and growth regulators. In: Stewart, W. D. P. (ed.) Algal physiology and biochemistry. Blackwell, Oxford, pp. 741-787

Ramamurthy, V. D. (1972). Procedures adopted for the laboratory cultivation of Trichodesmium erythraeum. Mar. Biol. 14: 232-234

Roman, M. R. (1978). Ingestion of the blue-green alga Trichodesmium by the harpactocoid copepod, Macrosetella gracilis. Limnol. Oceanogr. 23: 1245-1248

Saino, T. (1978). Biological nitrogen fixation in the ocean with emphasis on the nitrogen fixing blue-green alga Trichodesmium and its significance in the nitrogen cycling in the low latitude sea area. Ph. D. thesis, University of Tokyo

Saino, T., Hattori, A. (1978). Diel variation in nitrogen fixation by a marine blue-green alga, Trichodesmium thiebautii. Deep Sea Res. 25: 1259-1263 
Saino, T., Hattori, A. (1979). Nitrogen fixation by Trichodesmium and its significance in nitrogen cycling in the Kuroshio area and adjacent waters. The Kuroshio 4: $697-709$
Taylor, B. F., Lee, C. C., Bunt, J. S. (1973). Nitrogen-fixation associated with the marine blue-green alga, Trichodesmium as measured by the acetylene-reduction technique Arch. Mikrobiol. 88: 205-212

This paper was presented by Professor M. Anraku; it was accepted for printing on October 5, 1981 